\title{
Characterizations of Pectin/Lithium Sulfate Solid Biopolymer Electrolytes
}

\author{
M. Muthuvinayagam, M. Vahini, K. Sundaramahalingam
}

\begin{abstract}
In the present study, Pectin based Lithium sulfate added biopolymer electrolytes have been prepared by using Solution casting technique. Surface morphology of the prepared sample is investigated by Scanning Electron microscopy and crystalline nature is investigated by X-ray Diffraction. These films have a smooth surface and amorphous nature with good transparency. The Pectin is biopolymer which is ecofriendly and great abundance in earth. The maximum ionic conductivity value is obtained for 85Pectin:15Li2SO4 system. The change in ionic conductivity related to concentration of salt is also analyzed. The dielectric properties of the Pectin based system are also discussed.
\end{abstract}

Keywords : Pectin, FTIR, SEM, Ionic conductivity, dielectric constant.

\section{INTRODUCTION}

$\mathrm{R}$ Researchers have focused on the development of new materials for several applications with eco-friendly. The potential applications of biomaterials are numerous and involve different fields such as electrochemical devices, electro chromic devices, bio medical and so on [1-4]. The chemical polymers such as PVA, PVP, PEO, PMMA, PVC, and Pvdf are used to prepare the electrolytes for potential application in electrochemical devices [5-8]. In the field of energy storage materials, to produce new products from naturally available materials is used to avoid the environmental problems. Biodegradable natural polymers are used to prepare polymer electrolyte films for several applications. In the earlier reports reveals that the biopolymer based solid polymer electrolytes such as Pectin [9], Sodium alginate [10], agar-agar [2], cellulose acetate [11] and chitosan [12] are reported. The green polymer Pectin is used in this work which is a polysaccharide natural polymer, great abundance, acts as a cementing material in the cell walls of all plant tissues and so on [13]. In this present work, we have investigated the amorphous nature, morphology, ionic conductivity and dielectric behavior of

Revised Manuscript Received on December 29, 2019.

* Correspondence Author

M. Vahini, International Research Centre, Kalasalingam Academy of Research and Education, Anand nagar, Krishnankoil-626126 tamilnadu, India. Email: mvahini1991@gmail.com

M. Muthuvinayagam*, Department of Physics, Kalasalingam Academy of Research and Education, Anand nagar, Krishnankoil-626126, tamilnadu, India. Email: mmuthuvinayagam@gmail.com

K. Sundaramahalingam, International Research Centre, Kalasalingam Academy of Research and Education, Anand nagar, Krishnankoil-626126 tamilnadu, India. Email: sundaramahalingam07@gmail.com prepared biopolymer electrolytes.

\section{EXPERIMENTAL PROCEDURE}

In this present study, pectin and lithium sulfate has been used as precursor. The Pectin (polymer) and lithium sulfate (salt) with different ratios (100:00, 95:05, 90:10, 85:15, 80:20 and 75:25) were prepared. The solution casting method is used to prepare the all films. The distilled water is used as the solvent in throughout the work. Polymer and lithium sulfate were dissolved in distilled water separately. The polymer solution and lithium sulfate solution were mixed with constant stirring. At $303 \mathrm{~K}$, the mixture $(40 \mathrm{ml})$ was maintained in constant stirring until we get homogeneous solution. The resulting mixture solution was poured out into Petri dish and dried in an oven at $70{ }^{\circ} \mathrm{C}$ for 12 hours. After drying, the polymer electrolyte was separated from petri dish. The prepared polymer electrolytes are transparent and it is used to characterized.

\section{CHARACTERIZATION TOOLS}

The prepared biopolymer electrolytes were characterized by XRD, FTIR, SEM and AC-impedance studies. The amorphous nature of the electrolytes were analyzed by Xrd using $\mathrm{CuK \alpha}(\lambda=1.5406 \AA)$, Brukermade X-ray difractometer. The complex formations of prepared electrolytes were analyzed by FTIR using Shimadzu-IR Ainity-1 spectrometer instrument. By using Scanning Electron Microscope (SEM), the morphology of the biopolymer electrolytes are analyzed. Ionic conductivity measurement is made in the range of $42 \mathrm{~Hz}-1 \mathrm{MHz}$ at $303 \mathrm{~K}$ by using HIOKI 3532-50 LCR HI-TESTER Impedance analyzer.

\section{RESULTS AND DISCUSSION}

\section{A. XRD studies}

The degree of crystalline nature of all prepared lithium sulfate added pectin biopolymer electrolytes is shown in the Fig.1.The broad peaks between $14^{\circ}-17^{\circ}$ and around $30^{\circ}$, which can be associated with the semi crystalline nature of pure pectin. The crystalline nature of the pectin is decreased by addition of lithium sulfate. The diffraction peaks of pectin decrease in intensity and increase in broadness with an increase of lithium sulfate salt, which is denote the increasing amorphous nature of the biopolymer electrolytes system [13]. No peaks corresponding to lithium sulfate salt are observed in biopolymer electrolytes which indicate the absence of excess salt or 


\section{Characterizations of Pectin/Lithium sulfate Solid Biopolymer Electrolytes}

completely dissolved salt in the polymer matrix up to $20 \%$ salt added biopolymer electrolytes.

The increasing amorphous nature of the electrolytes is observed up to $15 \%$ of salt doped biopolymer electrolytes. After $15 \%$ of salt doped biopolymer electrolytes, there is an increase in intensity and some sharp peaks are observed. Because of increase in crystalinity nature biopolymer electrolytes is due to excess salt [14-15].

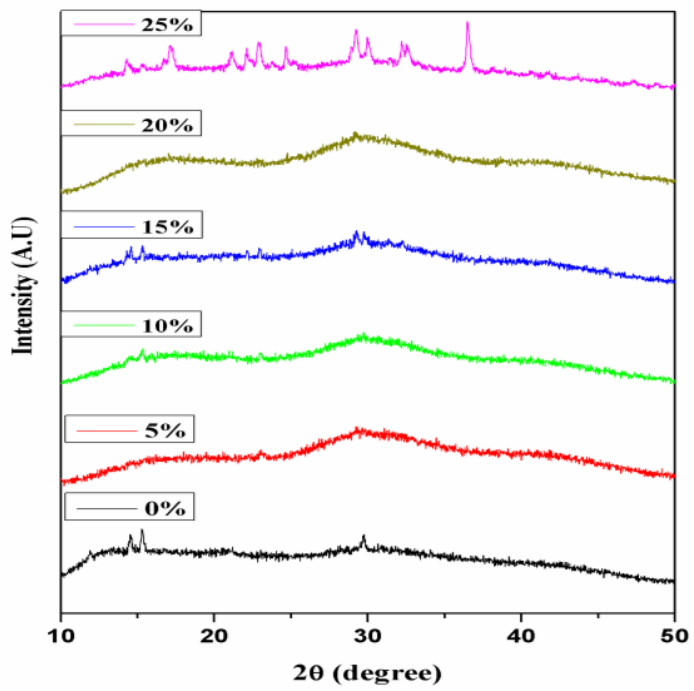

Fig.1 XRD pattern of Pectin: Lithium Sulfate (100:00, 95:05, 90:10, 85:15, 80:20 and75:25) biopolymer electrolytes

\section{B. FTIR-studies}

The occurrence of complexation between polymer and salt is confirmed by using FTIR studies. In the present work, the interaction between pectin and lithium sulfate is established by using FTIR studies. The change in the vibration modes of molecules can occur due to interactions. The band at $2933 \mathrm{~cm}^{-1}$ can be attributed to the vibration of C-H stretching of $\mathrm{CH}_{2}$ group in the pectin biopolymer. The interaction of the salt is shifted in this peak to $2937 \mathrm{~cm}^{-1}$ and $2920 \mathrm{~cm}^{-1}$. The stretching of $\mathrm{C}=\mathrm{O}$ of $\mathrm{COOCH}_{3}$ is observed at $1739 \mathrm{~cm}^{-1}$ and slight shift is also observed in this peak value at salt added biopolymer electrolytes.

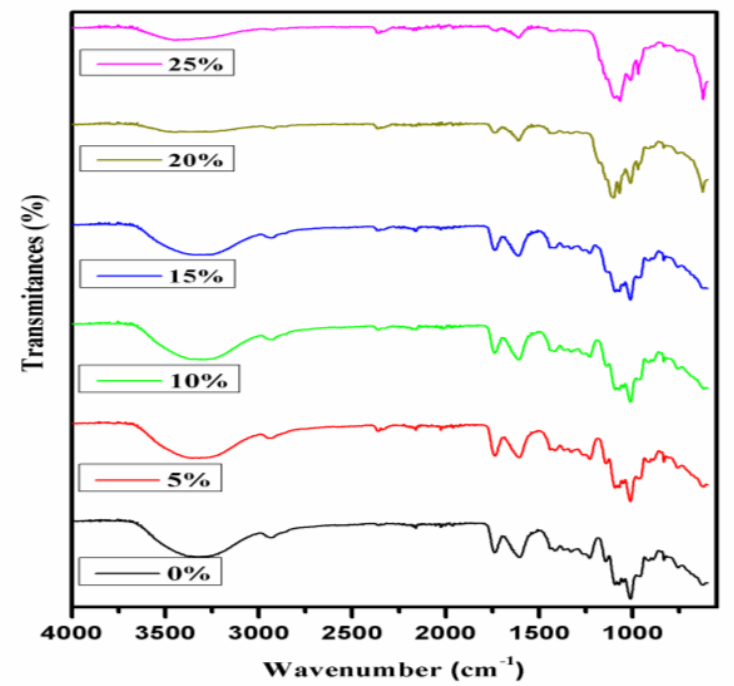

Fig.2 FTIR spectrum of Pectin: Lithium Sulfate (100:00, 95:05, 90:10, 85:15, 80:20 and75:25) biopolymer electrolytes

The peak at $1413 \mathrm{~cm}^{-1}$ is corresponding to vibration of $\mathrm{O}=\mathrm{C}-\mathrm{O}$ structure in the pectin. The presence of $-\mathrm{CH}-\mathrm{OH}$ in aliphatic cyclic secondary alcohol of pure pectin is observed at $1149 \mathrm{~cm}^{-1}$ and it is not observed in the $15 \%$ salt added biopolymer electrolytes due to more interaction of salt in this ratio compare to others. The peak at $1010 \mathrm{~cm}^{-1}$ suggests -CH-O-CH- stretching of pectin. The complex formation of pectin and $\mathrm{Li}_{2} \mathrm{SO}_{4}$ salt is confirmed by no peak at $1112 \mathrm{~cm}^{-1}$ for corresponding $\mathrm{Li}_{2} \mathrm{SO}_{4}$ salt. The $\mathrm{SO}_{4}{ }^{-}$ion of salt is interacted in the polymer matrix. The FTIR spectrum of all biopolymer electrolytes is shown in the Fig.2 [9, 14-16].

\section{SEM-analysis}

The morphology of the all prepared electrolytes are analyzed by using SEM-analysis. The Fig.3 (a-f) shows the SEM images of the lithium sulfate added pectin biopolymer electrolytes. The uniform surface morphology is obtained due to homogeneous mixture of polymer and salt. The porous homogenous texture nature is obtained in the $10 \%$ salt added polymer electrolytes and is increased in the $15 \%$ salt added polymer electrolytes. The insolubility of the salt is reflected in the $20 \%$ and $25 \%$ of salt added polymer electrolytes which is observed in the SEM-images. The maximum ionic conductivity is obtained in the $15 \%$ salt added polymer electrolytes due to the porous nature of the electrolyte film. The more amorphous nature and smooth morphology is obtained at $15 \%$ added salt added system. It is well close agreement of both XRD studies and SEM analysis [16, 17].
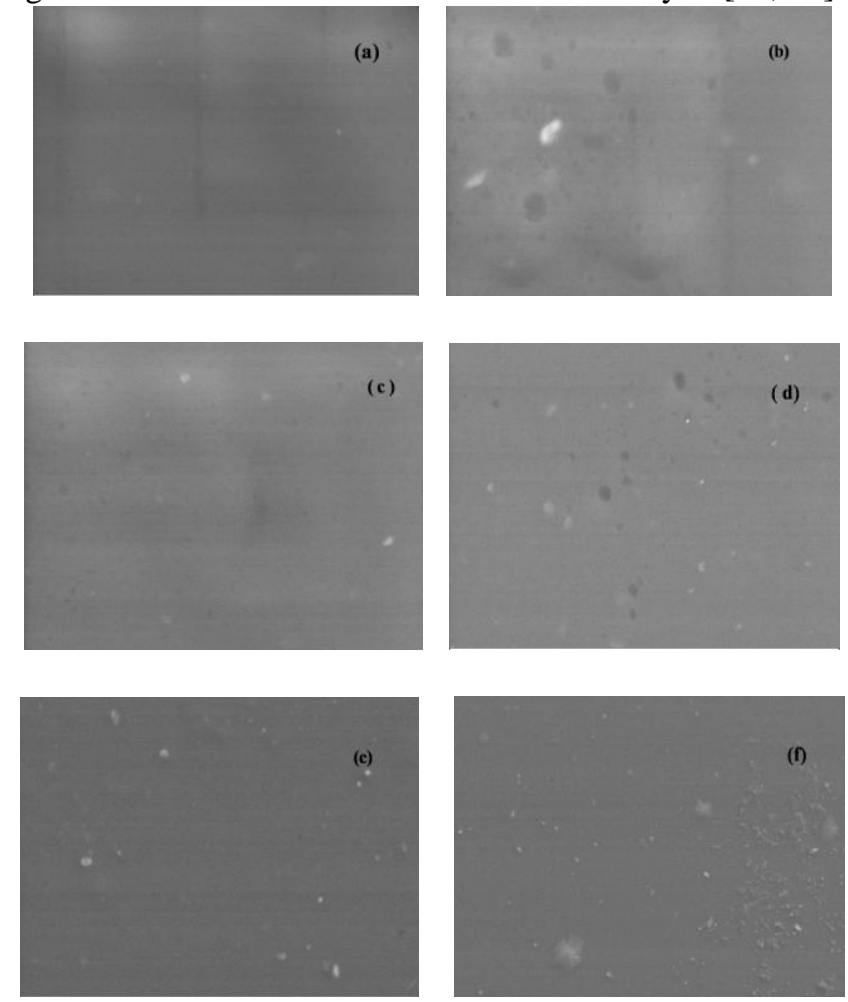

Fig.3 SEM images of Pectin:Lithium Sulfate biopolymer electrolytes (100:00, 95:05, 90:10, 85:15, 80:20 and75:25) $\mathrm{Mag}=5.00 \mathrm{~K}$ at $2 \mu \mathrm{m}$

\section{Ionic conductivity} studies

Cole-Cole plot 
The cole-cole plot of the prepared biopolymer electrolyte is shown in the Fig.4.

The bulk resistance of the sample is found by using the Z-view software by fitting of the cole-cole plot. Due to the effect of the blocking electrodes, the semicircle is formed in the high frequency region. The Slanted straight line is observed in the plot because of electrode electrolyte interfacial effect. The calculated bulk resistance and conductivity values of the sample is reported in the Table.1.The material conductivity or dc conductivity of the material is founded by using the conductance spectra and it is well matched with the value of the conductivity from colecole plot. The conductance spectra of the pectin based electrolytes are shown in the Fig.5 [14, 18]. The minimum bulk resistance and maximum ionic conductivity $\left(6.06 \times 10^{-8}\right.$ $\mathrm{S} / \mathrm{cm}$ ) is obtained at $15 \%$ salt added system. The reported value of ionic conductivity are calculated by using the formula, $\sigma=(\mathrm{t} / \mathrm{RbA})$ where $\sigma$ - is ionic conductivity, $\mathrm{t}$ - is thickness of film, A - is area of the film contacting the stainless steel disk electrodes, $\mathrm{Rb}$ - is bulk resistance of samples obtained from cole-cole plot.

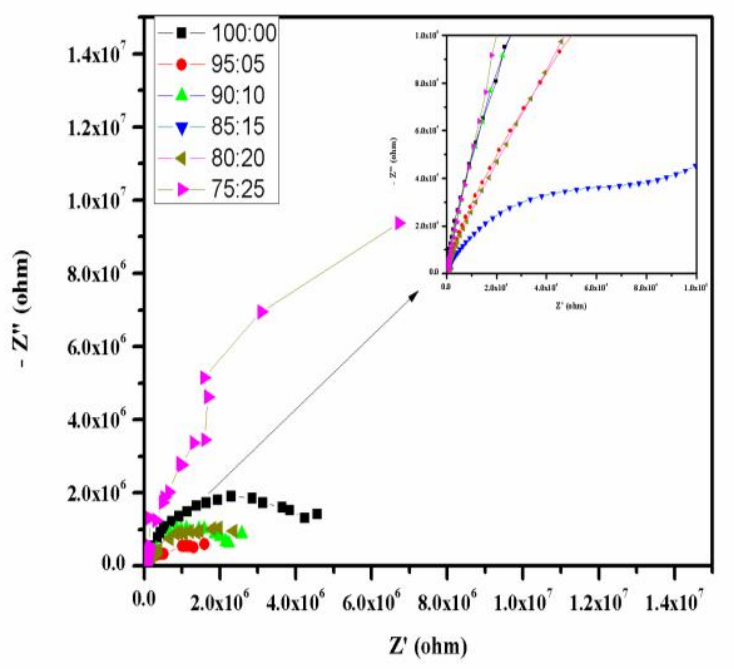

Fig.4 Cole cole plot for Pectin: Lithium Sulfate biopolymer electrolytes at room temperature

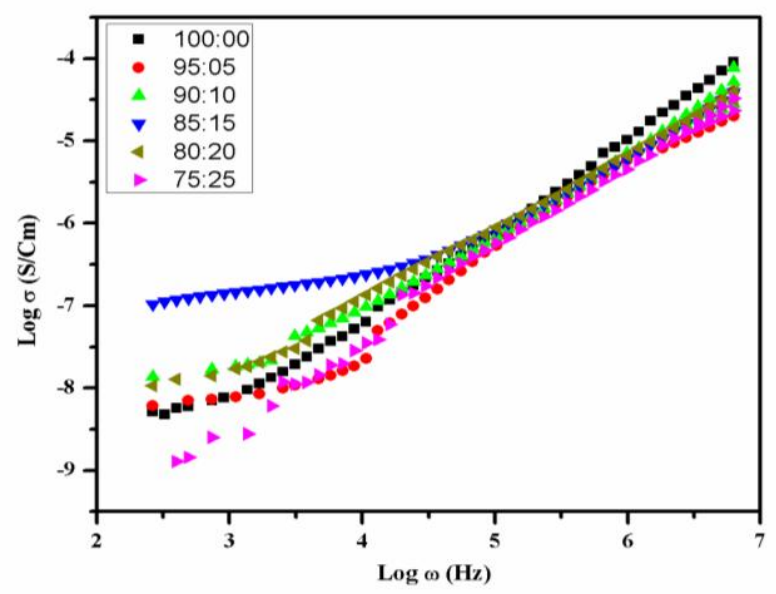

Fig.5 Conductance Spectra of Pectin:Li2SO4 biopolymer electrolytes at room temperature

Table. I Ionic conductivity of prepared system

\begin{tabular}{|r|c|c|c|}
\hline $\begin{array}{c}\text { S. } \\
\text { No }\end{array}$ & $\begin{array}{c}\text { Pectin: Lithium } \\
\text { Sulfate }\end{array}$ & $\begin{array}{c}\text { Bulk } \\
\text { Resistances }(\Omega)\end{array}$ & $\begin{array}{c}\text { Conductivity } \\
(\mathrm{S} / \mathrm{Cm})\end{array}$ \\
\hline 1 & $100: 00$ & $4.10 \times 10^{6}$ & $\begin{array}{c}2.68 \\
10^{-9}\end{array}$ \\
\hline 2 & $95: 05$ & $1.91 \times 10^{6}$ & $4.11 \times 10^{-9}$ \\
\hline 3 & $90: 10$ & $8.28 \times 10^{5}$ & $1.33 \times 10^{-8}$ \\
\hline 4 & $85: 15$ & $1.29 \times 10^{5}$ & $6.06 \times 10^{-8}$ \\
\hline 5 & $80: 20$ & $2.40 \times 10^{6}$ & $5.24 \times 10^{-9}$ \\
\hline 6 & $75: 25$ & $9.37 \times 10^{6}$ & $1.01 \times 10^{-9}$ \\
\hline
\end{tabular}

\section{Concentration dependent ionic conductivity}

The maximum ionic conductivity is observed for 85Pectin:15Li2SO4 system which is confirmed in both XRD and dielectric studies. The ionic conductivity of the biopolymer electrolytes is also depends upon the concentration of doping salt. The charge carriers are introduced by addition of salt into polymer matrix. At maximum ratio of salt can introduce the more number of charge carriers compare to the other ratio of salt added system. Due to the insolubility of salt and accumulation of charge carriers, the ionic conductivity get decreases above $15 \%$ of salt concentration $[3,6]$. The concentration dependent ionic conductivity is shown in the Fig.6.

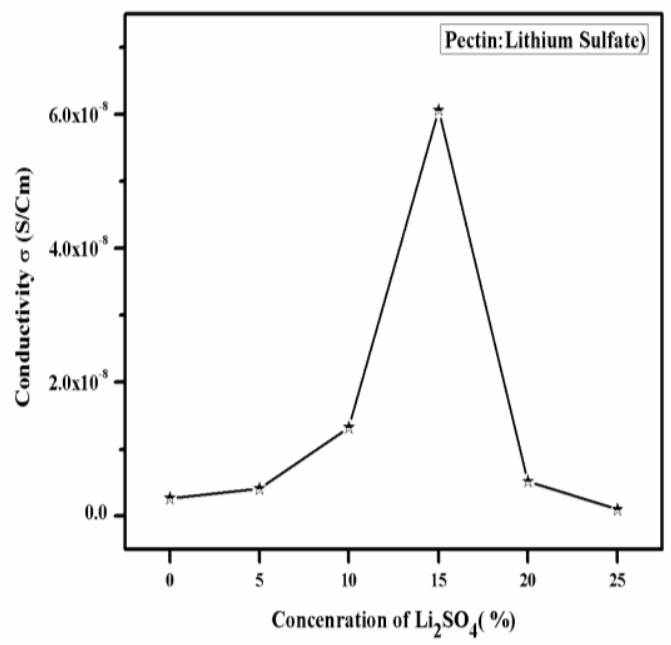

Fig.6 Concentration dependent ionic conductivity

\section{Dielectric spectrum}

The dielectric spectra are shown in the Fig.7.a \& Fig 7.b. The charge accumulation at the electrode-electrolyte interface gives the maximum dielectric constant at low frequency region. The decreases in the polarization at high frequency region affect the dielectric behavior of the material. Due to that the dielectric constant is decreased at high frequency region. The maximum dielectric constant and dielectric loss is founded for $15 \%$ of lithium sulfate added biopolymer electrolytes. The formation of space charge polarization with respect to the frequency is a reason for change in the dielectric constant with respect to frequency. The dielectric properties of the Pectin: lithium sulfate electrolyte reflects the non-Debye nature of the system [14]. 


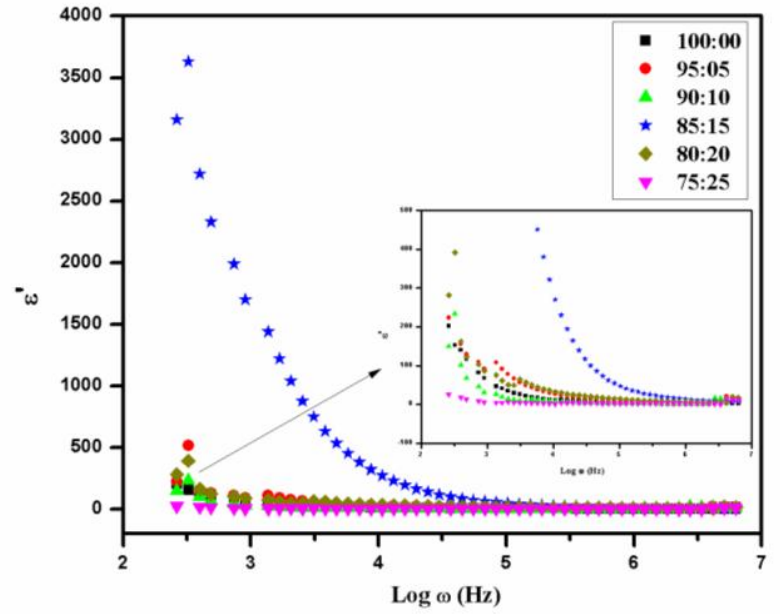

Fig.7.a Dielectric constant spectrum of Pectin: Lithium Sulfate biopolymer electrolytes (100:00, 95:05, 90:10, $85: 15,80: 20$ and 75:25) at room temperature

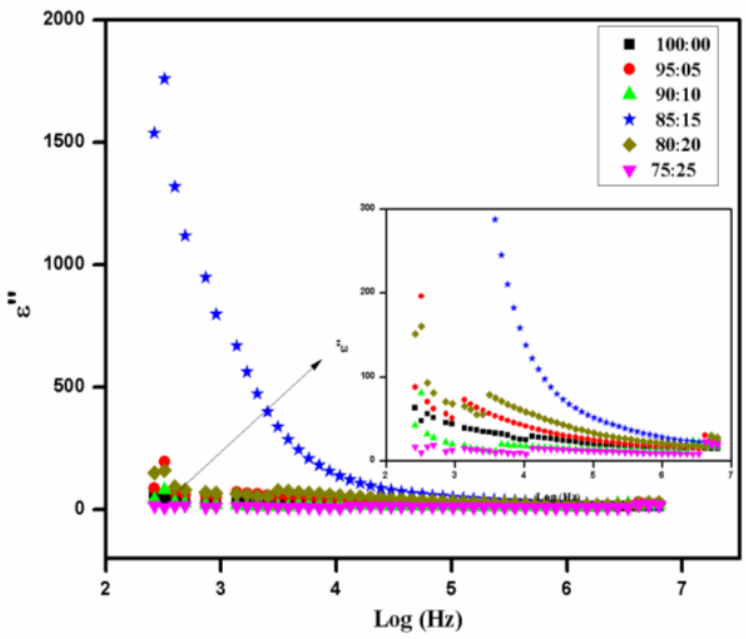

Fig.7.b Dielectric loss spectrum of Pectin: Lithium Sulfate biopolymer electrolytes (100:00, 95:05, 90:10, $85: 15,80: 20$ and 75:25) at room temperature

Tangent loss spectrum

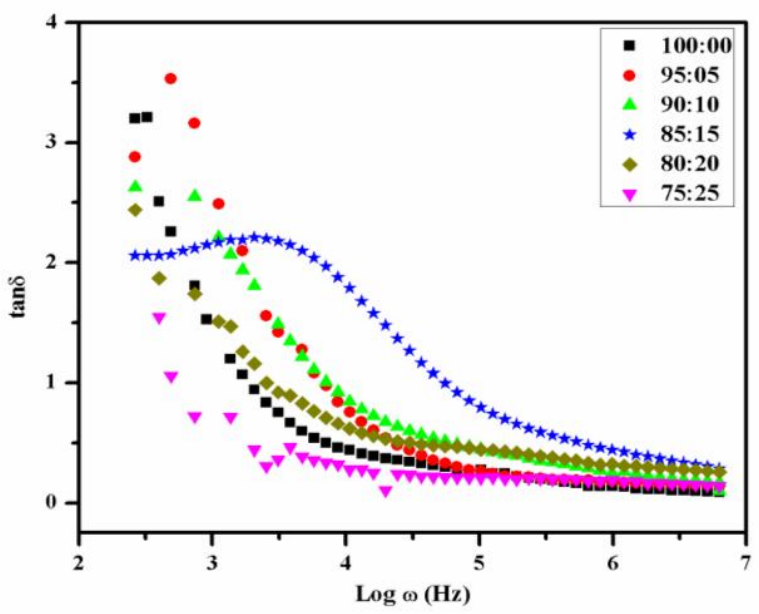

Fig.8 Loss Tangent spectrum of all Pectin: Lithium Sulfate biopolymer electrolytes at room temperature In Fig. 8 shows the tangent loss spectrum of prepared electrolyte system. Due to the interfacial polarization mechanism, the dispersion is observed at low frequency region. For $15 \%$ salt added biopolymer electrolyte has a peak at low frequency region is reflects the low relaxation time compare to the other electrolytes. It's well close in agreement with the conductivity analysis. The high dielectric constant, dielectric loss and low relaxation time obtained for $15 \%$ salt added biopolymer electrolyte which is confirmed by AC-Impedance studies [20 -21].

\section{CONCLUSION}

The biopolymer electrolytes based on pectin with addition of $\mathrm{Li}_{2} \mathrm{SO}_{4}$ was successfully prepared by Solution casting technique and it is analyzed by using XRD, FTIR, SEM and AC-Impedance studies. From XRD and FTIR studies, the amorphous nature and complex formation between pectin and lithium sulphate salt are conformed. The maximum ionic conductivity $6.06 \mathrm{E}-08 \mathrm{~S} / \mathrm{Cm}$ is obtained for $15 \%$ salt added biopolymer electrolytes. The maximum dielectric constant from dielectric spectra and minimum relaxation time from tangent loss spectra are obtained for same $15 \%$ salt added biopolymer electrolyte. The addition of filler and plasticizer can enhance the properties of pectin: lithium sulfate biopolymer electrolyte. Based on the AC-Impedance studies, the prepared biopolymer electrolyte has application in the energy storage devices.

\section{ACKNOWLEDGMENT}

The authors acknowledge the management of Kalasalingam Academy of Research and Education, Krishnankoil-626126, for providing research facilities with research fellowship.

\section{REFERENCES}

1. A.S. Samsudin, Wan M. Khairul and M.I.N. Isa. (2012) Characterization on the potential of carboxy methylcellulose for application as proton conducting biopolymer electrolytes, Journal of Non-Crystalline Solids, $358,1104-1112$

2. S. Selvalakshmi, N. Vijaya, S. Selvasekarapandian, M. Premalatha (2017) Biopolymer agar-agar doped with $\mathrm{NH}_{4} \mathrm{SCN}$ as solid polyme electrolyte for electrochemical cell application, Journal of Applied Polymer Science, 134, 44702.

3. Rahul Singh, Anji Reddy Polu, B. Bhattacharya, Hee-Woo Rhee, Canan Varlikli, Pramod K. Singh. (2016) Perspectives for solid biopolymer electrolytes in dye sensitized solar cell and battery application, Renewable and Sustainable Energy Reviews, 65, 1098-1117.

4. Jen-Ming Yang, Nian-Ci Wang, Hsien-Chih Chiu. (2014) Preparation and characterization of poly (vinyl alcohol)/sodium alginate blended membrane for alkaline solid polymer electrolytes membrane. Journal of Membrane Science, 457, 139-148.

5. Malaisamy Sethupathy, Subbiah Ravichandran, Paramasivam Manisankar. (2014) Preparation of PVdF-PAN-V $\mathrm{O}_{5}$ Hybrid Composite Membrane by Electrospinning and Fabrication of Dye-Sensitized Solar Cells, International Journal of Electrochemical Science, 9, 3166 3180 .

6. S. Abarna, G. Hirankumar. (2014) Vibrational, electrical, and ion transport properties of PVA-LiClO ${ }_{4}$-sulfolane electrolyte with high cationic conductivity, Ionics, 23 (7), 1733-1743.

7. Chun-Yi Chiu, Ying-Jie Yen, Shiao-Wei Kuo, Hsien-Wei Chen, Feng-Chih Chang. (2007) Complicated phase behavior and ionic conductivities of PVP-co-PMMA-based polymer electrolytes, Polymer $48,1329-1342$. 
8. S. Ramesh, Koay Hang Leen, K. Kumutha, A.K. Arof. (2007) FTIR studies of PVC/PMMA blend based polymer electrolytes, Spectrochimica Acta Part A, 66, 1237-1242.

9. R.K. Mishra, A.B.A. Majeed, A. K. Banthia. (2016) Synthesis, characterization and material properties of novel poly vinyl acetate grafted pectin, International Journal of Plastics Technology, 20, 79-92.

10. Y.O. Iwaki , M. Hernandez Escalona, J.R. Briones, A. Pawlicka. (2012) Sodium alginate-based ionic conducting membranes, Molecular Crystals and Liquid Crystals, 554, 221-231.

11. S. Monisha, T. Mathavan, S. Selvasekarapandian, A. Milton Franklin Benial, G. Aristatil, N. Mani, M. Premalatha, D. Vinoth pandi. (2017) Investigation of bio polymer electrolyte based on cellulose acetate-ammonium nitrate for potential use in electrochemical devices, Carbohydrate Polymers, 157, 38-47.

12. B. Smitha, S. Sridhar, A.A. Khan. (2005) Chitosan-sodium alginate polyion complexes as fuel cell membranes, European Polymer Journal, 41, 1859-1866.

13. J.P. Mendes, J.M.S.S. Esperança, M.J. Medeiros, A. Pawlicka, M.M. Silva. (2017) Structural, morphological, ionic conductivity, and thermal properties of pectin-based polymer electrolytes, Molecular Crystals and Liquid Crystals, 643, 266-273.

14. N. Vijaya, S. Selvasekarapandian, M. Sornalatha, K.S. Sujithra, S. Monisha. (2016) Proton-conducting biopolymer electrolytes based on pectin doped with $\mathrm{NH}_{4} \mathrm{X}(\mathrm{X}=\mathrm{Cl}, \mathrm{Br})$, Ionics, 23 (10), 2799-2808.

15. Juliana R. Andrade, Ellen Raphael, Agnieszka Pawlicka. (2009) Plasticized pectin-based gel electrolytes, Electrochimica Acta, 54, 6479-6483.

16. T. Uma, T. Mahalingam, U. Stimming. (2005) Solid polymer electrolytes based on poly(vinylchloride)-lithium sulfate, Materials Chemistry and Physics, 90, 239-244.

17. R. Leones, M.B.S. Botelho, F. Sentanin, I. Cesarino, A. Pawlickac, A. S S. Camargod, M.M. Silvad. (2014) Pectin-based Polymer Electrolytes with Ir(III) Complexes, Molecular Crystals and Liquid Crystals, 604, 117-125.

18. S. Selvasekarapandian, R. Baskaran, M. Hema. (2005) Complex AC impedance, transference number and vibrational spectroscopy studies of proton conducting PVAc- $\mathrm{NH}_{4} \mathrm{SCN}$ polymer electrolytes, Physica B 357, 412-419.

19. R. Baskaran, S. Selvasekarapandian, N. Kuwata, J. Kawamura, T. Hattori. (2006) Conductivity and thermal studies of blend polymer electrolytes based on PVAc-PMMA, Solid State Ionics, 177, 2679-2682.

20. R. Baskaran, S. Selvasekarapandian, N. Kuwata, J. Kawamura, T. Hattori. (2006) Ac impedance, DSC and FT-IR investigations on (x)PVAc- $(1-\mathrm{x}) \mathrm{PVdF}$ blends with $\mathrm{LiClO}_{4}$, Materials Chemistry and Physics, 98, 55-61.

21. N. Rajeswari, S. Selvasekarapandian, C. Sanjeeviraja, J. Kawamura. (2014) S. Asath Bahadur, A study on polymer blend electrolyte based on PVA/ PVP with proton salt, Polymer Bulletin, 71, 1061-1080.

\section{AUTHORS PROFILE}

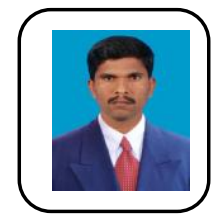

Dr. M. muthuvinayagam is an Associate professor in the Department of Physics, School of Advanced sciences at Kalasalingam Academy of Research and Education, India $\mathrm{He}$ obtained $\mathrm{PhD}$ in the area of polymer science from Madurai Kamaraj University at 2015 and M.Sc and B.Sc from Ayya Nadar Janaki Ammal college sivakasi. He has more experience in the polymer electrolyte for device application. He has published more than ten peer-review research articles in journals.

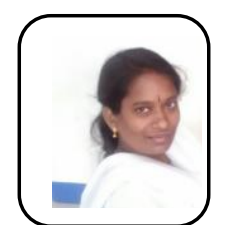

Dr. M. Vahini is a research scholar in the Department of Physics, School of Advanced sciences at Kalasalingam Academy of Research and Education, India. She obtained $\mathrm{PhD}$ in the area of polymer science from Kalasalingam Academy of Research and education at 2019 and M.Sc in Ayya Nadar Janaki Ammal college sivakasi and B.Sc at Sri Kaliswari college sivaksi. She has more experience in the polymer electrolyte for device application. She has published around seven peer-review research articles in journals.

Mr. K. Sundaramahalingam is a Research scholar in the Department of Physics, School of Advanced Sciences at Kalasalingam Academy of Research and Education, India. He is doing his $\mathrm{PhD}$ in the area of polymer electrolyte for battery applications. He has obtained M.Sc Degree in Physics at Ayya Nadar Janaki Ammal College, sivakasi and B.Sc. Degree in

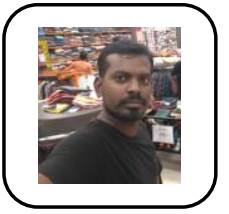

physics from Arulmigu Kalasalingam college of Arts and Science at Krishnankoil. He has published five peer-review research articles. 